\title{
Author Correction: Intravenous fluid therapy in critically ill adults
}

\section{Simon Finfer, John Myburgh and Rinaldo Bellomo}

Nature Reviews Nephrology (2018) https://doi.org/10.1038/s41581-018-0044-0

Published online 02 August 2018

In the original published version of this article, the Figures contained errors. In Figure 1, 'MAP' was added to the 'Salvage' box before '60-65 mmHg' and in Figure 3, 'Echocardiography' was changed to 'Electrocardiographic'. In Figure 4b, 'Intact' and 'Damaged' were added to the 'glycocalyx' labels and three new text labels 'Large pore transporting plasma proteins', 'Small pore network' and 'Intercellular cleft' were added to the left panel. Nuclei were added to the right-hand cells in both panels. The legend of Figure 4 was corrected to read "The colloid osmotic pressure in the sub-glycocalyx space is the principal determinant of transcapillary fluid flow. Fluid from the interstitial space can enter the vasculature through intercellular clefts, but the primary route by which fluid returns to the circulation is as lymph, as water absorption from afferent lymph in lymph nodes and as efferent lymph via the lymphatic ducts, notably the thoracic duct". These errors have been corrected for the HTML and PDF versions of the article.

Correction for Finfer, S., Myburgh, J. \& Bellomo, R. Intravenous fluid therapy in critically ill adults Nat. Rev. Nephrol. 14, 541-547 (2018). https://doi.org/10.1038/s41581-018-0044-0

https://doi.org/10.1038/s41581-018-0060-0 I Published online 4 October 2018 